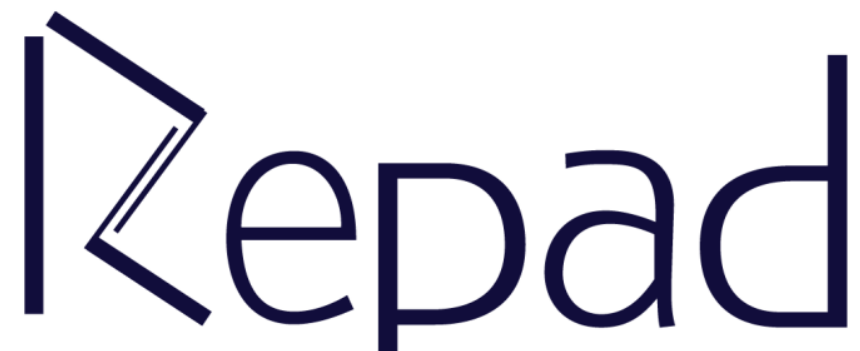

Vol. 2, n. 3, Dezembro/2018

Revista Estudos e

Pesquisas em Administração

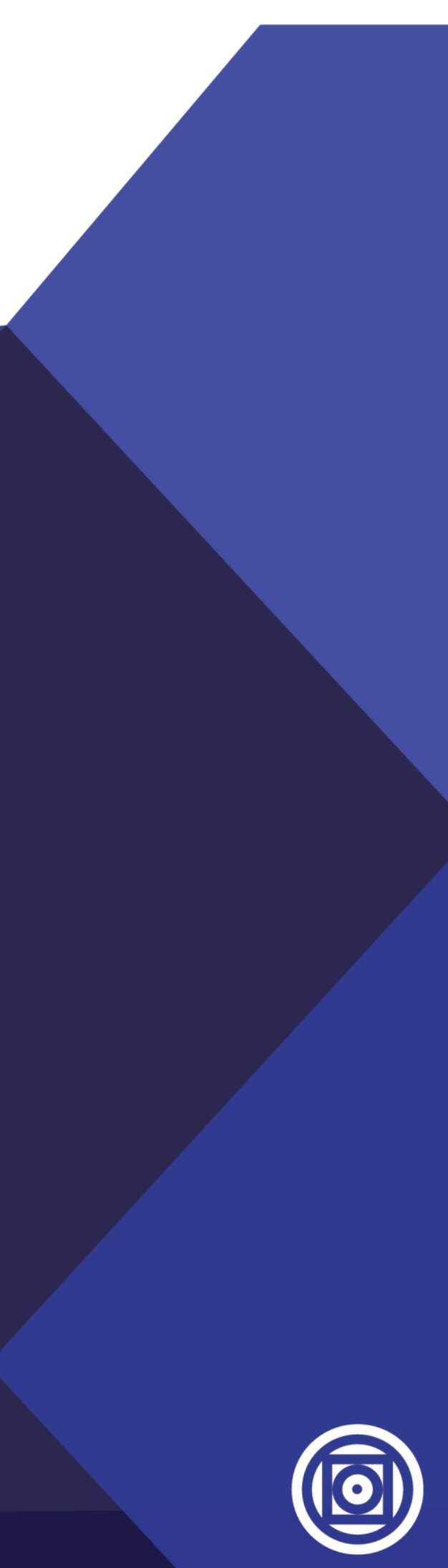




\title{
CONSELHOS GESTORES COMO ATORES PROPONENTES DE POLÍTICAS PÚBLICAS: Um estudo da Agenda-Setting
}

\author{
Vera Sirlene Leonardo \\ Universidade Estadual de Maringá \\ http://orcid.org/0000-0002-0199-2561 \\ Nilton Facci \\ Universidade Estadual de Maringá \\ http://orcid.org/0000-0002-2999-266X
}

\begin{abstract}
RESUMO
Este artigo discute a forma como um tema pode chamar a atenção dos políticos e burocratas e entrar na formação de agenda (agenda-setting) do governo. Tem por objetivo apresentar os projetos que emergiram das propostas do Conselho de Desenvolvimento Econômico (Codem), com destaque para aquelas que passaram a compor a agenda política do governo municipal de Maringá e previstas nos planos plurianuais. A pesquisa é empírico-teórica, descritiva, estudo de caso quanto à estratégia de pesquisa, cujo objeto empírico é o Codem e os dados foram levantados por meio de entrevistas e informações divulgadas no portal do município de Maringá. Os resultados mostraram quais foram as propostas do Codem que entraram na agenda e constaram no PPA como Programa ISS Tecnológico, o Prodem/empresa e Incubadora Tecnológica e outros por meio de leis municipais. Conclui-se que esse processo é permeado pelo conflito em que alguns temas entram na agenda e outros acabam sendo descartados.
\end{abstract}

Palavras-Chave: Formação da Agenda. Codem. Estratégia de Ação.

\section{MANAGER COUNCILS AS PUBLIC POLICY ACTORS: A Agenda-Setting study}

\begin{abstract}
This paper discusses how a subject can draw the attention of politicians and bureaucrats and be in the government's agenda-setting. The objective is to present the projects that emerged from the proposals of the Economic Development Council (Codem), with emphasis on those that became part of the political agenda of the local government of Maringá and foreseen in the multiannual plans. The research is empirical-theoretical, descriptive, case study regarding the research strategy, whose empirical object is the Codem and the data were collected through interviews and information published on the portal of the municipality. The results showed the Codem proposals that entered the agenda and were included in the PPA as ISS Technological Program, Prodem/company and Incubator Technological and others by municipal laws. It is concluded that this process is permeated by the conflict in which some subjects enter the agenda while others end up being discarded.
\end{abstract}

Keywords: Agenda-setting, Codem, Strategy of Action. 


\section{INTRODUÇÃO}

Desenhar políticas públicas que sejam capazes de impulsionar o desenvolvimento econômico e promover a inclusão social necessária a grande parte da população implica formar coalizões políticas capazes de equacionar detalhadamente a questão. As respostas a esse desafio não são fáceis nem consensuais. As regras que regem as decisões de elaboração da agenda governamental decorrem de conflitos inerentes à política pública explica Souza (2006).

Os conflitos vão desde as relações de poder entre os políticos (LINDBLOM, 1980, BRAGA, 2011) até as relações entre partidos políticos e grupos de interesse (EASTON, 1965; RESENDE, 2017), passando pela forma como se concebem as ideias e o conhecimento que influenciam o processo de políticas (FARIA, 2003, p. 23) e aos distintos interesses disputados pelos líderes políticos.

Todavia, fundamentado no estudo seminal de Tocqueville (2010, p. 85), de que nas "organizações locais a virtude cívica pode promover o bom governo sustentado por uma nova cultura política de liberdade e impulsionado pela própria sociedade civil", é que se busca compreender os parâmetros utilizados pelos diversos atores para influenciar na escolha de temas para entrar na formação da agenda política.

A literatura mostra que há uma multiplicidade de atores que podem influenciar na escolha de temas para entrar na formação da agenda (SOUZA, 2006; SERAFIN; DIAS, 2012; BENEDITO; MENEZES, 2013). Esta pesquisa elegeu, entre os possíveis atores, os representantes dos Conselhos gestores, mas especificamente o Conselho de Desenvolvimento Econômico (Codem) do município de Maringá.

A formação de agenda de políticas públicas é um tema que vem ganhando destaque no âmbito da gestão pública contemporânea, visto que busca explicar porque alguns temas são considerados prioritários e têm a preferência dos governos, enquanto outros não despertam a atenção dos governantes. Essa fase do ciclo de políticas públicas envolve a identificação do problema, a ascensão do tema (problema) na agenda e a seleção de alternativas para a solução do problema. No momento da elaboração da política há o confronto de ideias e interesses dos diversos atores que buscam identificar e selecionar as alternativas e as soluções políticas para os problemas sociais.

Neste artigo procurou-se avançar no sentido de combinar o tema agenda-setting com a capacidade/habilidade dos conselhos gestores em contribuir com ideias e conhecimentos que são absorvidos pelos gestores públicos e entram na pauta de discussão do legislativo/executivo.

Ampliar a participação social, mesmo que seja por ação normativa do Governo Federal, permite que diversos atores que possuem "conhecimento mais íntimo sobre a realidade local, levem para as instâncias decisórias informações relevantes para a solução ou minimização de problemas, formas de intervenção, monitoramento" e critérios para a avaliação dos resultados (TATAGIBA, 2003, p. 31). Ao participar o cidadão aprende não apenas a tomar decisões, mas a se orientar cada vez mais pelo interesse público. Por outro lado, as "instituições públicas ao ouvirem essas instâncias são induzidas a um aprendizado reflexivo que pode se traduzir em um fértil processo de reinvenção institucional" (TATAGIBA, 2003, p. 38).

Assim, diante da importância da participação de diferentes atores da sociedade civil organizada nas decisões quanto à proposição de ideias para agenda-setting de políticas públicas com vistas a fortalecer a democracia, este artigo tem por objetivo identificar os projetos que emergiram das propostas do Codem, e passaram a compor a agenda política do governo municipal de Maringá e foram inseridos nos planos plurianuais referente ao período de 2002 a 2017. 
Como problemática da pesquisa fica estabelecida a seguinte questão: Quais são as ações empreendidas pelo CODEM que resultaram nos projetos que influenciaram a agenda de políticas públicas junto ao governo do Município de Maringá? Isto porque, conforme veiculado na mídia local o Codem está consolidado como uma liderança política que emergiu da sociedade civil e que tem poder de influenciar fortemente decisões executivas e legislativas no que tange as negociações políticas e econômicas.

Após a fundamentação teórica, que discute o debate acadêmico sobre agenda, apresentase a metodologia seguida dos resultados da pesquisa que foram elaborados a partir da coleta dos dados e da interpretação das entrevistas realizadas. Por fim são apresentadas as considerações finais.

\section{O DEBATE ACADÊMICO SOBRE AGENDA}

Para elucidar a problemática desta pesquisa de mapear a influência do Conselho de Desenvolvimento Econômico de Maringá na definição da agenda de políticas públicas junto ao Governo do Município de Maringá discutem-se os principais constructos teóricos sobre o processo de Formação da agenda de políticas públicas.

Este artigo privilegia a análise sobre quando uma questão específica se torna importante num determinado momento, ao ponto de chamar a atenção do governo e passar a integrar a sua agenda. Diversos autores têm contribuído para a definição de agenda (SABATIER; JENKINSSMITH, 1993; CAPELLA, 2007; KINGDON, 2006a; SOUZA, 2007).

Primeiramente, cabe realçar que, entende-se por "políticas públicas um conjunto articulado de ações estatais orientadas para o enfrentamento de problemas públicos". Esse conceito, adotado por Farah $(2012$, p. 3), articula a política pública (Policy) ao conceito de sistema político (polity) e à política (Politics) e segue o mesmo entendimento de Frey (2000).

Convencionou-se pelos analistas de políticas públicas para descrever o policy cicle, em quatro estágios, podendo os diversos autores utilizar de nomenclaturas diferentes. Os estágios são: (1) agenda-setting ou a formação da agenda que se refere ao processo pelo qual os problemas chamam a atenção dos governos; (2) a formulação que se refere à definição de soluções adequadas e aceitáveis para o problema definido, a seleção dos atores envolvidos e à seleção de instrumentos de ação para a elaboração dos programas ou ações que poderão atingir os objetivos; (3) a implementação, que se relaciona ao modo como os governos dão curso efetivo a uma política; e (4) a avaliação que se refere aos processos pelos quais os atores monitoram os resultados da política avaliando a extensão dos impactos em relação ao problema inicial, a eficiência, a eficácia e a efetividade no sentido de corrigir os rumos da continuidade (JANN; WEGRICH, 2007).

Nesta pesquisa delimita-se ao estudo da agenda-setting. Para Cobb e Elder (1972, p. 44), agenda consiste na aplicação de "conhecimento a respeito dos conflitos sociais ao estudo da formação dos assuntos políticos". Saravia (2006, p. 33) explica que a "noção de inclusão na agenda designa o estudo e a explicitação do conjunto de processos que conduzem os fatos sociais a adquirir status de problema público, transformando-os em objeto de debates e controvérsias na política e na mídia".

$\mathrm{Na}$ acepção de Kingdon (2006a, p. 222), agenda corresponde à "lista de temas ou problemas que são alvo em dado momento de séria atenção, tanto da parte de autoridades governamentais como de pessoas fora do governo, mas estreitamente associadas às autoridades". Dias e Matos (2012, p. 71) exemplificam que a "agenda pode tomar forma de um programa de governo, um planejamento orçamentário, um estatuto partidário ou ainda uma 
simples lista de assuntos que se entendem prioridades do governo". O próprio dinamismo da vida política tem como consequência a entrada de uns temas na agenda e a saída de outros, e isto é tido como um fato natural explica o mesmo autor.

Nem toda situação ou problema social é foco da atenção de políticos e burocratas e entra na agenda governamental. A possibilidade de um tema ganhar proporções e assumir lugar de destaque maior é se ele estiver associado a um problema importante naquele momento. "As situações passam a ser definidas como problema e aumentam as suas chances de se tornarem prioridade na agenda, quando acreditamos que devemos fazer algo para mudá-las" (KINGDON, 2006b, p. 227). "Somente a convicção de que um problema social precisa ser dominado política e administrativamente o transforma em um problema de policy" defendem Windhoff-Héritier (1987, apud Frey, 2000, p. 227). Fuks (2000) argumenta no mesmo sentido, ao colocar que a condição para determinado tema passar a ser objeto de atenção é o reconhecimento de que é um problema público e, portanto, deixa de ter apelo apenas individual e passa a interferir na dinâmica social pública.

Kingdon (2003) indaga por que alguns problemas se tornam importantes para um governo? Como uma ideia ${ }^{1}$ se insere no conjunto de preocupações dos formuladores de políticas, transformando-se em uma política pública?

As abordagens que destacam o papel das ideias e do conhecimento no processo das políticas públicas têm sido praticamente ignoradas no Brasil, afirma Faria (2003). De acordo com o autor, não há consenso entre os estudiosos na "maneira, na medida e no grau em que se concebe o modo como as ideias e o conhecimento influenciam ou constituem as ações".

Segundo Gottems et al. (2013), a agenda governamental segue um processo não intencional que se caracteriza por: (1) surgimento ou reconhecimento de um problema pela sociedade em geral; (2) existência de ideias e alternativas originadas de especialistas, investigadores, políticos e atores sociais, dentre outros; (3) contexto político, administrativo e legislativo favorável ao desenvolvimento da ação (KINGDON, 2003; BONAFONT, 2004; FERRAREZI, 2007; ZAHARIADIS, 2007; CAPELLA, 2007).

No estudo seminal de Cobb e Elder (1972, p. 14), os autores questionam: Como é construída a agenda, isto é, como é que um determinado assunto ganha acesso a ela? E quem participa deste processo? Nesta pesquisa a discussão está centrada na segunda questão colocada por Cobb e Elder (1972) limitando-se a mostrar quais são os demais atores que participam do processo de definição de assuntos públicos, além de burocratas e políticos eleitos e quais são os temas sugeridos por esses atores. Neste artigo discute-se quais são os temas que entram na agenda advindos do Codem, com destaque para as formas adotadas por esse ator político para participar do processo de definição da agenda de políticas públicas a serem executadas pelo Poder Executivo Municipal.

\section{METODOLOGIA}

Para melhor elucidar o problema da pesquisa, optou-se pela abordagem qualitativa. A pesquisa qualitativa é rigorosa, exige trabalho intenso, integridade e um exercício de julgamento por parte do investigador, que incluem a reflexividade e a atenção aos casos desviantes e à

\footnotetext{
${ }^{1}$ Por ideias entende-se afirmação de valores, especificação de relações causais, soluções para problemas públicos, símbolos ou imagens que expressam identidades públicas e privadas, até mesmo concepções de mundo e ideologias de acordo com John (2006).
} 
relevância (AUGUSTO, 2014). Ela depende do pesquisador na produção do conhecimento: habilidade, conhecimento e rigor na coleta dos dados (POZZEBON, 2014).

Nesse tipo de pesquisa o pesquisador vai a campo para captar o fenômeno em estudo a partir da perspectiva das pessoas nele envolvidas, considerando todos os pontos de vista relevantes (GODOY, 1995). Ela propicia o aprofundamento da complexidade de fenômenos e processos particulares (MINAYO; SANCHEZ, 1993).

A estratégia da pesquisa é o estudo de caso que, segundo Stake (2005), é um caminho natural para conduzir pesquisas qualitativas. Pozzebon (2014) explica que o estudo de caso em profundidade consiste em um veículo metodológico adequado para o desenvolvimento de pesquisas qualitativas em pesquisas na administração pública, pelo leque de possibilidades que se abre para a compreensão dos significados.

Trata-se de um estudo de caso único com procedimentos de coleta de dados por meio de entrevistas semiestruturadas ${ }^{2}$, realizadas pessoalmente, gravadas e transcritas posteriormente. Participaram das entrevistas o ex-secretário do Codem e a ex-secretária executiva, 3 (três) conselheiros e 4 (quatro) ex-conselheiros, 2 (dois) vereadores e 3 (três) servidores públicos. As entrevistas tiveram duração de aproximadamente quarenta minutos.

Para fins de assegurar o anonimato dos entrevistados, principalmente por tratar-se de personalidades públicas, optou-se pela não divulgação nominal para não os identificar.

Para subsidiar e validar os dados coletados, a pesquisa apoiou-se em documentos institucionais, site institucional, atas e leis. É uma pesquisa descritiva e como unidade de análise utilizou-se o posicionamento dos entrevistados quanto às atividades do Codem, delimitando a análise ao período de 2002 a 2017.

Uma pesquisa científica, numa abordagem qualitativa, é realizada num movimento contínuo de fases interligadas. É uma dinâmica de idas e vindas, no esforço de amadurecer o objeto de estudo; de delimitar o problema de investigação; de coletar os dados que respondam ao problema da pesquisa e de tratar os dados coletados e interpretá-los (BOOTH, COLOMB e WILLIANS, 2008).

A análise dos dados é considerada um dos grandes desafios da pesquisa qualitativa. A complexidade e muitas vezes ambiguidade do volume de palavras, frases e diferentes contextos podem dificultar a análise do pesquisador diz Langley (1999). É na ansiedade de organizar os dados e poder decidir o que é relevante ou não, que o pesquisador pode desviar-se dos seus propósitos e tirar conclusões precipitadas. É preciso ir além das descrições superficiais para penetrar na lógica que se encontra escondida na observação direta (LANGLEY, 1999).

É uma técnica refinada de interpretação de dados, mas também exige muita dedicação, paciência e tempo do pesquisador, o qual tem de se valer da intuição, imaginação e criatividade, principalmente na definição de categorias de análise. Para tanto, disciplina, perseverança e rigor são essenciais (FREITAS, CUNHA, e MOSCAROLA, 1997). Para Chizzotti (2013), a análise de conteúdo visa compreender criticamente o sentido das comunicações, o seu conteúdo manifesto ou latente e as significações explícitas ou ocultas. Entre as diferentes e possíveis formas de análise de dados utilizou-se nesta pesquisa a análise de conteúdo proposta por Bardin (2002).

O produto final da análise de uma pesquisa, por mais brilhante que seja, deve ser sempre encarada de forma provisória e aproximativa, conforme explica Minayo (2002). Essa colocação

\footnotetext{
${ }^{2}$ É um tipo de entrevista mais espontânea do que a entrevista estruturada. O entrevistador tem um conjunto de questões predefinidas, mas mantém liberdade para colocar outras cujo interesse surja no decorrer da entrevista. As questões pré-definidas são uma diretriz, mas não ditam a forma como a entrevista irá decorrer, na medida em que as questões não têm de ser colocadas numa determinada ordem nem exatamente da mesma forma com que foram inicialmente definidas (TOZONI-REIS, 2005).
} 
tem por base que em se tratando de ciência, as afirmações podem superar conclusões prévias a elas e podem ser superadas por outras afirmações futuras. Assim é o percurso da ciência. $\mathrm{O}$ conhecimento científico não cresce de modo cumulativo e contínuo; ele é descontínuo e opera em saltos qualitativos (KUHN, 2013).

\title{
O CODEM E SUA TRAJETÓRIA PARA COMPOR A AGENDA MUNICIPAL
}

De acordo com Silva (2015) foi devido a ação coordenada pela Associação Comercial e Industrial de Maringá (ACIM) na década de 1990, em reação à crise econômica do país e consequentemente do município de Maringá, que dentre outras justificativas, criou-se o Codem. Em meados da década de 1990, a economia local sentiu os efeitos da estagnação econômica do país e alguns setores foram comprometidos, especialmente muitas empresas atacadistas de confecções e facções industriais, que eram as grandes geradoras de empregos na região (CODEM, 2011).

\begin{abstract}
ACIM mobilizou grande parcela da sociedade para encontrar uma saída à recessão econômica local que era acentuada em decorrência da disputa de dois grupos políticos antagônicos (Said Ferreira e Ricardo Barros), que na visão do empresariado paralisava a cidade (SILVA, 2015, p. 175).
\end{abstract}

A articulação dos membros da ACIM para a criação do Codem intensificou-se com a proximidade das eleições de 1996 promovendo eventos setoriais e debates sobre o direcionamento da cidade. Foi convocado um fórum para discutir a vocação da cidade, para repensá-la, relata Silva (2015). Durante o "ano foram realizados 105 eventos setoriais para ouvir e arrolar propostas e contribuições de grande parte da sociedade civil organizada" (CODEM, 2011, p. 10).

Os eventos setoriais envolveram os mais variados setores da sociedade: sindicatos patronais, sindicato de trabalhadores, associações empresariais, associações de classe, igrejas, clubes de serviços, organizações não governamentais, Universidade Estadual de Maringá e representantes dos poderes constituídos (CODEM, 2011).

Esses eventos ficaram conhecidos como "Repensando Maringá" e culminou com a proposta de futuro para Maringá em 2020. Esse documento, que consolidava as demandas da coletividade sob uma perspectiva de 24 anos adiante, teve como resultados: (a) a disponibilização para a comunidade e a divulgação ampla pelos meios de comunicação, das demandas que representaram o compromisso compartilhado por todos; (b) a sociedade local estava organizada e passava a ter objetivos comuns a perseguir; (c) consolidava-se o comprometimento da sociedade civil organizada com a definição e a construção do futuro do município.

O conselho passou a ser gerido por representantes das entidades da sociedade civil organizada; com caráter deliberativo e consultivo em assuntos de desenvolvimento econômico; com estrutura para possibilitar o fórum de debates; com espaço para a elaboração de estudos e formulação de propostas de políticas públicas de desenvolvimento econômico.

Os membros que fazem parte do conselho pertencem a diferentes setores da economia como comércio varejista, prestação de serviços, pequena indústria e de profissionais liberais. Participam da composição do Codem, segundo Gini (2009), vários segmentos não empresariais como sindicatos de trabalhadores, universidades, entidades não governamentais e clubes de serviços. O entrevistado 1 explica que os profissionais, ao participarem do conselho, podem 
contribuir cada um com a sua expertise, dentro da sua área de atuação, tais como os arquitetos e urbanistas que participam do plano diretor ou dos Planos Locais de Habitação de Interesse Social (Plhis).

Isto pode ser observado em Silva (2015) quando a autora relata que houve a aprovação de leis urbanísticas propostas pelo Conselho sem qualquer emenda, caso até então inédito que sinaliza a predominância de um consenso entre os atores públicos e o Codem. "Além do processo de aprovação das leis, a ideia de repensar a cidade é explicita até mesmo na lei do Plano Diretor, tendo como princípio a intenção de reinventar uma nova Maringá (SILVA, 2015, p. 182).

Após dez anos da implantação do Codem, o organismo deliberou por fazer uma avaliação para verificar se a cidade idealizada para 2020 evoluiu ou se estava evoluindo no caminho desejado. Disto, resultou no documento Maringá 2030 formado por um conjunto de objetivos para o município, diretrizes orientadoras do processo e de estratégias de condução. E em 2016, o Codem apresentou o projeto “Masterplan ${ }^{3}$ Metrópole Maringá 2047”, contendo um planejamento para quando a cidade completar 100 anos:

O presidente do Codem, Luiz Fernando Ferraz, esteve ontem na Câmara Municipal para apresentar o relatório do projeto Maringá 2030. O texto foi elaborado nas câmaras técnicas do Codem, com a participação de 315 pessoas e 93 entidades representativas da sociedade maringaense. O projeto estabelece diretrizes para a cidade alcançar nos próximos 19 anos (SIMÕES, 2011, p.1).

Prestes a ter a primeira fase concluída, o Projeto "Masterplan Metrópole Maringá 2047" foi apresentado, nesta sexta-feira (dia 2), aos oito candidatos que disputam a prefeitura de Maringá. A apresentação foi em uma reunião na sede da ACIM, gestora do projeto junto com o Codem (ACIM, 2016a, p.1).

A ACIM entende que é imprescindível que as gestões municipais se comprometam a adotar as diretrizes do planejamento. O prefeito Roberto Pupin assinou um convênio comprometendo-se a utilizar o plano socioeconômico para suporte de planos diretores. Espera-se que as próximas administrações municipais, dada a importância do projeto, façam o mesmo (ANUÁRIO DA ECONOMIA, 2016, p. 43).

De acordo com a literatura analisada, o Codem, tem participação ativa no controle político da cidade influenciando diretamente na formulação dos planos estratégicos da cidade que vieram a ser elaborados e nortearam as ações dos sucessivos gestores a partir da década de noventa" (SILVA, 2015, p. 175). A atuação desse conselho tem representado uma força dirigente capaz de assumir o controle político da cidade, mesmo sem participar diretamente do processo eleitoral (GINI, 2007).

\footnotetext{
${ }^{3} \mathrm{O}$ Masterplan como planejamento de toda uma cidade é inédito no Brasil, mas projetos como este já foram implantados em Singapura, Perth (Austrália), Coreia do Sul e Nova Iorque (EUA), entre outros países. (ANUÁRIO DA ECONOMIA, 2016). O projeto levou dez meses para ser realizado e envolveu lideranças do município e dez consultores da PricewaterhouseCoopers (PwC) que fizeram entrevistas individuais e analisaram mais de três mil indicadores econômicos e sociais. O projeto bancado pela iniciativa privada custou $\mathrm{R} \$ 1$ milhão, na primeira fase (CODEM, 2016). Foi custeado por dezenas de empresas, incluindo as de grande porte e também pequenos empresários, como os que integram o Núcleo de Postos de Combustíveis, os taxistas, um grupo de 22 restaurantes, hotéis, locadoras de carro e pessoas físicas, que podem, por exemplo, doar milhas aéreas para viabilizar o deslocamento dos profissionais que irão trabalhar na execução do Masterplan (VIEIRA, 2016, ACIM, 2016).
} 
Em recente publicação da revista Exame sobre a pesquisa realizada pela Consultoria Macroplan em que Maringá foi considerada, pelo segundo ano consecutivo, melhor cidade do Brasil, o atual prefeito Ulisses Maia, ressalta o trabalho do Codem:

O grande salto da cidade foi dado em 1996, com a fundação do Conselho de Desenvolvimento Econômico de Maringá (Codem), um braço da associação empresarial e comercial da cidade. Em períodos eleitorais, os candidatos a prefeito precisam adequar as propostas às diretrizes do Codem. Os gestores públicos não podem criar políticas e projetos sem consultar o Codem, diz o prefeito. Tudo é discutido e cada ação é planejada e se insere num objetivo maior (EXAME, 2018).

Pode-se categorizar a atuação do conselho, segundo Gini (2009) como de ordem: (1) técnica: coletar as ideias que emanam dos debates, realizar de estudos para organizá-las na forma de projeto ou ação e retornar para ver se realmente sintetiza os desejos da plenária (2) tática: que se refere à forma de abordagem, a forma como os temas das agendas são construídos e amarrados entre si, principalmente para que o cumprimento de um item force a execução de outros e (3) estratégica: está relacionada com a ação coletiva em si. Quem fala pelo Codem?

Estrategicamente quem negocia? Como transformar as ideias em tema da agenda do executivo? Como elaborar e divulgar os documentos ${ }^{4}$ que apresentam e justificam as reivindicações? Como retratar a posição assumida pelo Executivo diante das demandas? Para evidenciar essa atuação o conselho estabelece os objetivos das propostas para 0 desenvolvimento econômico local e regional:

Tornar-se uma cidade economicamente desenvolvida, com elevados níveis de emprego e riqueza e com renda mais equitativamente distribuída, com modelo econômico que garanta forte crescimento, ambiental e tecnologicamente sustentável e que tenha como fim último o desenvolvimento social, consolidando-a como centro de excelência em educação, em saúde, em infraestrutura logística e em desenvolvimento tecnológico, exportadora de tecnologia para o mundo e reconhecida como centro de comércio internacional (CODEM, 2008).

Para que os objetivos do Codem fossem alcançados fez-se necessário criar uma comissão de estudo, para organizar e sistematizar as ideias soltas que surgiam nas discussões das câmaras, buscar soluções ou alternativas para os problemas e então retornar o tema para o

\footnotetext{
${ }^{4}$ Um dos documentos é o Plano de Desenvolvimento de Maringá (CODEN 1998, p. 68 à 87), que estabelece as políticas de desenvolvimento do conselho que foram direcionadas para oito áreas estratégias: 1) área comunitária: crescimento da cidade até 500 mil habitantes com qualidade de vida (o que significa, melhor distribuição de renda, educação, saúde, saneamento, segurança e transporte) com cultura e sociedade civil organizada; 2) área universitária: transformar-se em centro de excelência em ciência e tecnologia (formação empreendedora); 3) área de integração tecnológica: crescimento com desenvolvimento social, controle e preservação ambiental; 4) área de investimentos: criar oportunidades de negócio, tanto com aproveitamento dos vazios setoriais quanto alongamento da cadeia produtiva. Investimentos em turismo e lazer; 5) área de agricultura e agroindústria: consolidar-se como polo agro alimentar de base tecnológica e empresarial forte, diversificada e internacionalmente competitiva; 6) área de comércio e serviços: polo de excelência em serviços de educação, saúde e eventos; 7) área de comércio exterior: portal do Brasil, Mercosul e resto do mundo; 8) área de gestão empresarial: instalação de incubadoras tecnológicas e centro de empreendedorismo.
} 
debate na respectiva câmara, de forma consolidada, para avaliar a comissão tinha realmente absorvido os desejos dos membros das câmaras fala um entrevistado.

Isto porque as câmaras representam o espaço onde surgem tanto as ideias, as demandas, as propostas de soluções e/ou alternativas para os problemas levantados com foco naquilo que se pensa representar o melhor para o município, como também os argumentos por aumentar ou garantir privilégios e apelos para a manutenção ou agregação de interesses. Muitas ideias eram novas e relevantes socialmente, outras eram replicação de ideias que deram resultado em outros municípios. Nas entrevistas ficou registrado o depoimento de que era "muito difícil" escolher entre diversas alternativas, de modo que algumas ideias sobreviveram intactas, outras eram confrontadas e associadas em novas propostas, outras surgiram dos estudos que a comissão realizava. Foi destacado que algumas propostas eram consideradas inviáveis e acabavam sendo descartadas.

A diretoria do Codem e seu comitê gestor eram os responsáveis pelo orquestramento das ideias que vingavam em diversos fóruns, meios de comunicação, site institucional, seminários e audiências públicas no sentido de sensibilizar os representantes das instituições públicas, demais associações e o público em geral para conseguir a sua aceitação comenta um dos entrevistados. O uso da persuasão acompanhada de indicadores que mostravam a realidade a ser mudada/melhorada era frequentemente utilizado para ganhar mais adeptos.

\title{
ESTRATÉGIA DE AÇÃO DO CODEM PARA UM TEMA FAZER PARTE DA FORMAÇÃO DA AGENDA
}

Pelas entrevistas buscou-se entender as formas de atuação dessa entidade, composta por diferentes atores articulando temas de políticas públicas. Segundo um dos entrevistados, "[...] nós dificilmente conseguiremos fazer com que um tema entre na agenda, somente porque é expectativa da comunidade" e explica que:

\begin{abstract}
Propor e não propor não significa nada, dá na mesma, não sai do papel. Um político chegou a falar: quem foi eleito com mais de cem mil votos fui eu, porque vocês acham que podem intervir no meu governo [...] verificou-se que levar ao legislativo ou executivo um tema, mesmo sendo a demanda de mais de duzentos e cinquenta entidades não era o caminho adequado para conseguir com que esse tema entrasse na agenda. Então como fazer com que o executivo comprasse a ideia? [...] Aí foi redefinida a estratégia de ação do Codem [...] Passaram a solicitar que representantes das diversas secretarias fossem participar das discussões.
\end{abstract}

Denota-se o quão complexo é fazer com que um tema seja incluído na agenda de governo. Diante dos argumentos do entrevistado, a estratégia para que um tema ganhasse força era ter o apoio de políticos e burocratas. E isso somente seria possível, se os membros do governo estivessem, também, participando do Codem e fazendo parte das diversas etapas da discussão dos temas. Assim, se o assunto era de crescimento e planejamento urbano, por exemplo, participaria um burocrata da Secretaria de Desenvolvimento Econômico. O presidente de honra seria o prefeito eleito. Assim, conforme destacou um dos entrevistados "todos os assuntos, todas as proposições nasciam em conjunto com a participação direta dos encarregados da execução para que eles sentissem que a ideia era também deles". Segundo um dos membros fundadores do Codem, as ideias selecionadas associadas ao saber técnico e científico dos 
membros do conselho ou de consultorias $^{5}$ contratadas eram apresentadas devidamente acompanhadas das alternativas a serem adotadas, com a definição do público-alvo e a previsão dos benefícios a serem alcançados. "Tudo estrategicamente estudado com colaboração da expertise dos membros do conselho de acordo com a sua área de atuação [...]. Foi então que o Codem adquiriu força e conseguiu que várias das suas propostas entrassem na agenda [...] foi um aprendizado [...]" enfatiza um entrevistado.

Apesar dos conflitos, muitas propostas do conselho conseguiram entrar na agenda do governo conforme mostra o Quadro 1:

Quadro 1: Temas ${ }^{6}$ propostos pelo conselho que entraram na agenda

1) Programa ISS Tecnológico ${ }^{7}$ : $\underline{O}$ que é? Consiste em conceder benefícios fiscais para microempresas prestadoras de serviços que realizarem investimentos para pesquisa e desenvolvimento tecnológico no Município de Maringá e se modernizarem investindo em software. Como surgiu a ideia? Curitiba e Londrina já desenvolviam esse projeto com sucesso. Os estudos técnicos realizados mostram que podia ser replicado em Maringá para manter e fortalecer as pequenas empresas de serviços incentivando a compra de equipamentos e dando mais recursos para elas crescerem e fomentarem os negócios das empresas de software que estão instaladas no município. Que necessidade motivou o programa? O setor de Tecnologia da Informação é significativo no município e a utilização de tecnologias locais visa promover a modernização e inovação de investimentos em pequenas empresas e o dinamismo nos dois setores. É uma forma de incentivar a geração de empregos, a pesquisa e o desenvolvimento tecnológico de pequenas empresas.

2) Programa de Desenvolvimento Econômico de Maringá (Prodem)/empresa: O que é? Visa fomentar a expansão de empreendimentos já existentes e estimular a atração de novos empreendimentos no município de Maringá, com o fim primordial de gerar novos empregos e renda. Como surgiu a ideia? Para atrair investimentos no município e buscar uma contrapartida do município com a promoção de incentivos às empresas na aquisição de terrenos, isenção do Imposto Predial e Territorial Urbano e Imposto Sobre Serviços; executar infraestrutura primária em terrenos destinados à implantação dos empreendimentos. Que necessidade motivou o programa? Atrair investimentos para o município junto as empresas interessadas em empreender que possam contribuir para alavancar a atividade econômica com a criação de novos empregos o que leva a melhorar os Indicadores de Qualidade de Vida com vistas a promover o desenvolvimento local sustentado.

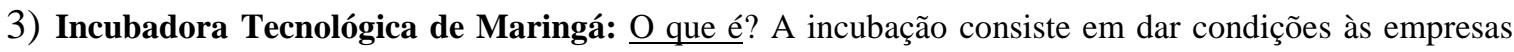
para desenvolverem produtos, processos e serviços inovadores. Como surgiu a ideia? Para dar apoio às empresas de base tecnológica como forma de facilitar a transferência de tecnologia, know-how, o desenvolvimento de produtos, processos ou serviços com emprego de tecnologias inovadoras. Que necessidade motivou o programa? A busca de promover o desenvolvimento Científico e Tecnológico do município pela criação de novas oportunidades de trabalho e a melhoria de desempenho dos negócios no nível local e regional. Estimular a geração de empreendimentos inovadores e promover e integração entre universidade, centros de pesquisas, empresas e a comunidade.

\section{Fonte: Documentos consultados}

Esses temas entraram na agenda do executivo local e permanecem até hoje. No caso do Programa ISS Tecnológico, a Lei Complementar nº 975/2013 dispõe sobre a criação do

\footnotetext{
5 "Maringá foi planejada para ter 110 mil moradores, um número muito aquém dos mais de 400 mil atuais. Mas como proporcionar crescimento econômico e populacional, sem perder qualidade de vida? A resposta está no planejamento. E é isto que a sociedade civil organizada está fazendo ao contratar consultorias para elaborar o Masterplan, que ajudará a planejar a cidade até 2047, quando Maringá terá cem anos [...] (ANUÁRIO DA ECONOMIA, 2016, p. 40, 43).

${ }^{6}$ Os temas elencados no quadro 01 foram compilados de documentos fornecidos pelo Codem. Além disso, essas informações estão presente na fala de diversos entrevistados.

${ }^{7}$ Transformou-se na Lei ${ }^{\circ}$ 1455/2013.
} 
Programa ISS Tecnológico e institui os benefícios fiscais para as empresas prestadoras de serviços que realizarem investimentos para pesquisa e desenvolvimento tecnológico no município de Maringá. Já no caso da Incubadora, a Lei no 9790/2014 criou o parque industrial tecnológico, denominado Incubadora Tecnológica de Maringá, e a Lei n ${ }^{\circ}$ 10.407/2017 regulamenta os mecanismos e medidas de incentivo à inovação, à pesquisa tecnológica e à consolidação dos ambientes de inovação nos setores produtivos e sociais na cidade de Maringá.

O Quadro 2 apresenta um tema que permaneceu na agenda durante várias gestões, recebendo aporte financeiro do governo municipal, entretanto na gestão passada o governo resolveu não mais apoiar o projeto por considerá-lo muito arrojado para o município de Maringá, segundo a fala de um dos entrevistados.

Quadro 2: $\mathrm{Tema}^{8}$ proposto pelo conselho que entrou na agenda por determinado período de tempo

Parque Tecnológico de Maringá (TECNOPARQ) e Maringá Tecnópolis: O que é? Um condomínio tecnológico indutor para o desenvolvimento regional formado por empresas com a vocação tecnológica e inovadora cujas áreas são dedicadas às instalações industriais, laboratoriais, administrativas e de lazer com amplo foco em áreas verdes e na sustentabilidade. Os estudos contemplam a modelagem institucional e de gestão para a governança do empreendimento segundo um modelo inovador de parceria público-privada. Como surgiu a ideia? Das experiências de sucesso na implantação de parques tecnológicos de Saint Laurent, na região de Montreal e Quebec. Seriam alternativas para o desenvolvimento local, a geração de novos empregos, a criação de pequenas empresas, particularmente as de base tecnológica e a revitalização de economias locais, e evitar a fuga de talentos jovens da área de informática que se formam na universidade e faculdades locais. Que necessidade motivou o programa? Interpretando as propostas construídas para MARINGÁ 2020 sobre as políticas de desenvolvimento econômico a implantar identificou-se a necessidade da criação de um espaço que conseguisse reunir e articular ativos e equipamentos tecnológicos colocados em convivência com empresas de base tecnológica. A proximidade física a outras empresas e instituições, em particular universidades e centros de pesquisa, amplia as possibilidades de estabelecer cooperações. Assim, seria construída uma base técnica aglutinadora de pesquisadores e lideranças para participar e transferir conhecimento e tecnologia.

Fonte: Documentos consultados

"Por meio do discurso do desenvolvimento e da retomada do crescimento, o conselho empreendeu uma forma de ação política que alcançou resultados significativos junto ao Executivo", afirma Gini (2009, p. 3). Refere-se à elaboração e apresentação de uma agenda propositiva para os candidatos ao executivo em 2000, pontuando os anseios e as perspectivas do Codem. Segundo o mesmo autor o documento intitulado "O que Maringá espera do novo governo", tratava de um planejamento para políticas públicas de desenvolvimento econômico que presumia colocar a cidade na rota dos grandes investimentos e retomar o seu perfil de cidade próspera.

No documento Contribuições do Codem encontram-se mais de sessenta propostas e/ou ações discutidas e encaminhadas aos poderes constituídos como propostas de políticas no período de 1997 a 2013. A origem das ideias propostas é muito dinâmica pode surgir de estudos de oportunidades desenvolvidos pela equipe técnica ou, como disse um entrevistado, da participação de um conselheiro em "algum evento de inovação, dentro ou fora do país, que vivenciou um case sobre leis de inovação municipal, fundos, ou leis de incentivos e traz a experiência para conselho", ou de um conselheiro que participou:

[..] de uma feira no setor do vestuário fora do Brasil e eventualmente viu uma questão urbanística que traz para o conselho e a equipe técnica vai investigar

\footnotetext{
${ }^{8}$ As informações contidas no quadro 2 foram retiradas de documentos fornecidos pelo Codem. Tais informações foram ratificadas por diversos entrevistados.
} 
um pouco mais, depois vamos abrir a discussão, buscar contribuições entre os membros e o tema vai tomando corpo e pode evoluir em projeto, edital ou termo de referência.

"Já ocorreu de muitas experiências trazidas pelos conselheiros serem apropriadas às questões que estavam sendo discutidas no momento e acabavam se materializando", relatou a então secretária-executiva do Codem. Muitas soluções chegam para resolver problemas que já haviam sido levantados. Um problema não pode ser suscetível de dúvidas, tem que convencer a comunidade da sua importância e, portanto, para entrar na agenda precisa investir na argumentação. No Quadro 3, acrescentam-se algumas outras propostas e o critério selecionado para apresentá-las foi a menção a elas por alguns dos entrevistados.

\section{Quadro 3: Propostas, Projetos, Ações e Contribuições do Codem}

\begin{tabular}{|c|}
\hline $\begin{array}{l}\text { ontaminação do Subsolo, Lençol Freático e Córregos de Maringá por rejeitos primários foi uma } \\
\text { roposta encaminhada aos poderes locais que culminou com a Audiência Pública e com a alteração de leis e } \\
\text { ódigos. Resultou na formulação e aprovação da Lei de Zoneamento Ecológico de Maringá. Esse estudo } \\
\text { umpriu parte da diretriz de desenvolvimento sustentável definida pelo Conselho de Desenvolvimento } \\
\text { conômico de Maringá, no documento Maringá } 2020 \text {. }\end{array}$ \\
\hline $\begin{array}{l}\text { Projeto do Agropólo para a Região da AMUSEP: visa a Integração Regional, Cadeias Produtivas } \\
\text { Definidas, Integração Institucional, Inovação Tecnológica, Objetivos Comuns e Agente Catalisador que } \\
\text { resultou na criação do Selo de Qualidade para Produtos Regionais; criação de um Serviço de Inspeção } \\
\text { Regional de Sanidade; criação de curso técnico de nível médio em agronegócios, qualificação de mão de obra, } \\
\text { com recursos do FAT, apoio institucional para as cadeias produtivas escolhidas; estímulo às Associações de } \\
\text { Produtores e Incentivo a Criação de Outras; criação de Unidades Pilotos de Produção. }\end{array}$ \\
\hline $\begin{array}{l}\text { Reciclagem de Embalagens de Agrotóxicos nas Propriedades Rurais. Estudo de caráter técnico e } \\
\text { econômico, indicando a possibilidade de aproveitamento desse tipo de embalagem, criando, com isso, um } \\
\text { maior interesse pelo seu recolhimento, armazenamento e destinação adequados. }\end{array}$ \\
\hline $\begin{array}{l}\text { Apoio a Coopercicla: Viabilizou sua implantação. O projeto consistiu na realização de campanha para alocar } \\
\text { recursos destinados ao financiamento da aquisição de carrinhos para equipar os catadores de lixo reciclável } \\
\text { ligados à Cooperativa. }\end{array}$ \\
\hline $\begin{array}{l}\text { Reflorestamento das Matas Ciliares. Iniciativa do CODEM, mas não logrou o êxito esperado, uma vez que } \\
\text { dependia de articulação entre entidades públicas nos vários níveis de governo, o que deixou a desejar, } \\
\text { principalmente em razão do pequeno interesse destas. }\end{array}$ \\
\hline $\begin{array}{l}\text { Pólo da indústria têxtil e da confecção. Transformar a indústria de confecção local e regional, de indústria } \\
\text { de roupa para indústria de moda. Maringá é um centro produtor de moda e, segundo o segmento, este ainda } \\
\text { não sentiu o efeito China em suas atividades e, provavelmente, estará livre da concorrência meramente de } \\
\text { preço. }\end{array}$ \\
\hline $\begin{array}{l}\text { Organização do Sistema de Saúde de Maringá. O documento Maringá } 2020 \text { previa transformar a cidade } \\
\text { num pólo de excelência em serviços de saúde. A proposta feita foi de um sistema com gestão unificada feita } \\
\text { por uma Fundação Privada com participação pública e que envolvia todos os ativos públicos estaduais, } \\
\text { municipais e, eventualmente, federais e filantrópicos. O projeto foi submetido à administração municipal para } \\
\text { apreciação. Nesse ínterim houve alteração na administração municipal e a nova gestão entendeu que o modelo } \\
\text { proposto não atendia à sua proposta de gestão municinal }\end{array}$ \\
\hline
\end{tabular}
Fonte: Codem (2016).

Adiciona-se que a própria aprovação no legislativo da criação do Codem, como entidade articuladora de interesses entre a sociedade civil organizada e as instituições políticas locais é um tema que entrou na agenda em 1997 e tem se mantido desde então. Foi uma ideia incubada no nível local. No site institucional estão relatados alguns desdobramentos das ações do Codem, além daquelas citadas nos Quadros 1 a 3, que são (1) as inúmeras comitivas de associações, representantes da sociedade civil e governamental que vem ao município de Maringá para 
conhecer essa experiência de participação para replicar ${ }^{9}$ nos moldes de projetos estratégicos de futuro e (2) as viagens dos diretores a convite de outros municípios ou capitais para realizar palestras sobre a forma de organização e coordenação da entidade.

Nas propostas do Codem, constata-se: (a) a articulação das ideias para compor a agenda de políticas locais com objetivos claros de desenvolvimento socioeconômico ligado ao ramo tecnológico, (b) metas de inovação, (c) diagnóstico de oportunidades de mercado (d) o envolvimento dos poderes públicos legalmente instituídos no município na atração de determinado benefício para uma região específica da cidade e (e) a articulação com outros atores, como investidores imobiliários e universidades.

Esses resultados, por um lado fazem com que, mais do que apenas um receptáculo, o município torna-se o catalisador do desenvolvimento de um polo tecnológico inovador, tanto pela economia tecnológica, quanto pela recuperação de um contexto urbano. Por outro lado, nota-se o fortalecimento e empoderamento da classe empresarial no nível local. Entretanto, de forma indireta a sociedade é beneficiada quando o cunho dessas propostas é incentivar a geração de empregos, a pesquisa e o desenvolvimento tecnológico das empresas estabelecidas no município.

Para confrontar se as realizações divulgadas nas publicações locais e no site do Codem estavam presentes nos planos de governo foi efetuado levantamento no Plano Plurianual (PPA) de 2002 a 2017 do município de Maringá. Pode-se constatar:

Na função (22) indústria, subfunção (661) Promoção Industrial consta a ação (0006.13) Implantação do Parque Tecnológico de Maringá - Tecnoparq no valor de R \$ 3.532.000,00.

Na função (22) indústria, subfunção (661) Promoção Industrial consta a ação (0006.14) Infraestrutura para parques e áreas industriais no valor de R \$ 5.523.218,00. Na ação (0006.13) Implantação do parque tecnológico de Maringá, Tecnoparq, no valor de R \$151.000,00.

Quanto ao Programa ISS Tecnológico e Prodem nada aparece no PPA, contudo é uma realidade uma vez que existem leis municipais que regulamentam e os programas estão em andamento, conforme entrevista com diretor da Secretaria de Desenvolvimento Econômico.

$\mathrm{Na}$ composição do conselho analisado, constatou-se a forte presença de empresários e também de pesquisadores vinculados à academia e consultorias contratadas. $O$ suporte da academia e das consultorias é conceber mecanismos de coordenação de estudos, de reunir informações para dar suporte no levantamento do problema, identificar os benefícios para a sociedade e prover com argumentos que unifiquem as suas decisões. Para os empresários o apoio especializado permite o enfrentamento dos obstáculos inerentes à situação econômica, social e política, em ação conjunta. Atuando em conjunto tem maior probabilidade de sucesso na articulação com os poderes constituídos, além de firmar os elementos democráticos de participação.

\section{CONSIDERAÇÕES FINAIS}

Com o olhar voltado para a realidade local procurou-se identificar se a sociedade civil organizada do município de Maringá tem instrumentos para articular com políticos e burocratas temas tidos como preocupações com o desenvolvimento do município. Concluiu-se que os conselhos gestores podem ser esses instrumentos. Foi definido, então, como objeto empírico da

\footnotetext{
${ }^{9}$ Montes Claros, município de Minas Gerais, formalizou do seu Conselho de Desenvolvimento Econômico que será chamado de CODEMC, utilizando as experiências de Maringá.
} 
pesquisa, o Codem, conselho idealizado por representantes da sociedade civil organizada, que tem desenvolvido atividades para pensar o município no longo prazo.

Pode-se dizer que a própria criação do conselho foi propiciada pela conjuntura econômica e política favorável para um problema entrar na agenda e trouxe novos atores com poder político de atuação junto aos poderes legalmente instituídos alcançando sucesso em lutar pelas suas demandas em um grupo que compartilha das mesmas questões.

Como desafios na proposição de temas para a agenda de políticas públicas está o conflito e a disputa permanente por espaço para elencar temas e prioridades que emergem das discussões entre os conselheiros das câmaras técnicas mostraram as entrevistas.

Contudo, o limite de atuação do conselho está na tentativa do executivo local em fazer prevalecer as suas próprias propostas de governo. A tensão e conflito nas negociações entre os atores estão presentes na fala dos entrevistados. As negociações para a aprovação de determinados temas podem levar meses até gestões, quando da mudança de prefeito. Pode-se concluir como limite de atuação do conselho a presença dos atores estatais na sua composição, por outro lado, somente trazendo esses atores a participar das ideias é que se consegue a aprovação de temas para a agenda.

Entretanto, a pesquisa mostrou que para um tema fazer parte da agenda-setting a relevância é a condição inicial para caracterizar a necessidade de priorizar um problema. A relevância de um assunto e o sentimento de que um tema tem relevância para a comunidade nasce de muitas formas. Uma delas é trabalhar para compreender a realidade social e mostrar como o tema é importante. Os principais desafios para o avanço efetivo de uma participação que pretende ampliar e melhorar os resultados das políticas públicas é o pensar no coletivo em defesa dos interesses sociais.

Foram desenvolvidos saberes no Codem que conseguiram construir uma consciência sobre o problema do pensar coletivo. A construção dessa ideia de consciência coletiva passa a ser um fator poderoso e determinante para a definição da agenda. Esse é um conselho que adquiriu poder político nas questões econômicas locais. Os conselheiros vão para as reuniões munidos de argumentos técnicos e científicos fundamentados por dados, gráficos e tabelas, de modo a construir base de apoio no sentido de defender um tema na plenária que tenha aceitação da maioria dos membros. Mesmo com essas ações, o grande desafio que se percebeu pelas entrevistas é a construção do consenso, conforme destacam os quadros 2 e 3.

Para responder ao problema de pesquisa apresentou-se as inúmeras ações e algumas inseridas no PPA conforme apresentado no texto, que aqui se caracterizou com o alcance desse conselho na proposição de temas para a agenda de políticas públicas.

Como alcance do conselho analisado está a ação de intervir quando os poderes públicos legalmente instituídos não dão conta das políticas públicas de desenvolvimento econômico, entendidas como prioritárias no nível local. Essa intervenção dos representantes da sociedade civil organizada que participam do Codem é no sentido de agir politicamente na busca de soluções apropriadas para resolvê-lo, algumas vezes com sucesso, outras nem tanto. Como alcance registram-se, também, os resultados da entidade no levantamento de problemas e a estratégia de conscientizar a opinião pública para a importância de buscar soluções para os temas que despontam.

Destaca-se como alcance que o conselho possui força política e econômica perante várias gestões do governo municipal, independentemente de partido. Esse poder político significa trabalho em parceria na área econômica e de desenvolvimento com todos os prefeitos. "O Codem tem à disposição pessoal técnico e qualificado que pensa projetos de desenvolvimento para a cidade" no longo prazo diz um entrevistado. 
É exemplo de uma ação local que tem se mostrado capaz de dar uma resposta para as questões da sociedade civil organizada e o poder público favorecendo a complementariedade, a transversalidade e a integração entre as instâncias da democracia representativa, participativa e direta, além de fortalecer a capacidade do cidadão de exercerem a accountability.

Políticos e burocratas são atores que tem uma atuação mais influente na definição da agenda por participar intensamente dos fluxos de problemas e de política e, portanto, são responsáveis pela criação das oportunidades de acesso à agenda governamental. Contudo, não se pode ignorar o alcance dessa categoria de atores reunidos sob a capa de conselho que também são determinantes na escolha de alternativas, atuando principalmente sobre a agenda de decisão, com ideias, propostas, estudos e projetos.

É uma iniciativa pioneira do município de Maringá e dá conta estabelecer uma mesa de diálogo, mecanismo de debate e de negociação com a participação dos setores da sociedade civil e do governo diretamente envolvidos no intuito de prevenir, mediar e solucionar conflitos sociais.

Pela análise dos dados pode-se concluir que grandes transformações produtivas no município de Maringá apoiaram-se na intervenção política do Conselho de Desenvolvimento Econômico de Maringá nos temas da agenda e a sua presença é forte nas decisões econômicas tomadas pelo setor público.

\section{REFERÊNCIAS}

ACIM. Associação Comercial e Industrial de Maringá. Lançamento do Masterplan reúne lideranças e empresários. Portal de Notícias da Acim:10/03/2016. Disponível em: https://www.acim.com.br/portal/noticias. Acesso em: Dez/2016.

- Candidatos a prefeito de Maringá conhecem Masterplan. Disponível em: https://www.acim.com.br/portal. Acesso em: dez/2016a.

ANUÁRIO DA ECONOMIA 2016-2017. A grande região de Maringá. Edição Especial: Masterplan Metrópole Maringá. Maringá: CBN/ACIM, 2016.

AUGUSTO, A. Metodologias quantitativas/metodologias qualitativas: mais do que uma questão de preferência. Fórum Sociológico, n. 24, 2014.

BARDIN, L. Análise de conteúdo. Lisboa: Casagraf-Artes Gráficas Unipcssoal Lda, Edições 70, 2002.

BENEDITO, A. MENEZES, D. F. N. Políticas públicas de inclusão social: o papel das empresas. Revista Ética e Filosofia Política. n. 16, v. 1. Jun/2013.

BOOTH, W.C.; COLOMB G.G.; WILliAnS J. M. A arte da pesquisa. São Paulo: Martins fontes, 2008.

BONAFONT, L. C. Redes de políticas públicas. Madrid: Centro de Investigaciones Sociológicas, 2004. 
BRAGA, S. Poder, formas de dominação e Estado no diálogo entre Nicos Poulantzas e a sociologia política norte-americana. Revista Brasileira de Ciências Políticas, n.5. Brasília, 2011.

CAPELLA, A. C. N. Perspectivas teóricas sobre o processo de formulação de políticas públicas. In: HOCHMAN, G. et al. Políticas públicas no Brasil. Rio de Janeiro: Fiocruz, 2007.

CESÁRIO, P. Redes de influência no Congresso Nacional: como se articulam os principais grupos de interesses. Revista de Sociologia Política. v. 24, n. 59, p. 109-127, set. 2016.

CHIZZOTTI, A. Pesquisa em ciências humanas e sociais. São Paulo: Cortez, 2013.

CODEM-Conselho de Desenvolvimento de Maringá - Coletânea de documentos, Maringá: CODEM, 1998.

. O que Maringá espera do novo governo. Conselho de Desenvolvimento Econômico de Maringá, 2008.

Cidades inovadoras: uma visão de futuro. Maringá 2030. Codem-Conselho de Desenvolvimento Econômico de Maringá, 2011.

- Masterplan: entrega do plano socioeconômico. Notícias Masterplan. Disponível em: http://www.codem.org.br/. Acesso em dez/2016.

COBB, R.; ELDER, C. Participation in American Politics: the dynamics of agenda-building. Baltimore: The Johns Hopkins University Press, 1972.

DIAS, R.; MATOS, F. Políticas públicas: princípios, propósitos e processos. São Paulo: Atlas, 2012.

EASTON, D. A Framework for Political Analysis. Englewood Cliffs: Prentice Hall. 1965.

EXAME. O segredo de cidades que melhoram mesmo na crise. Economia.7/082018. Disponível em: https://exame.abril.com.br/economia. Acesso em: 09 set. 2018.

FARAH. M. Análise de políticas públicas no nível municipal de governo. $\mathbf{8}^{\circ}$ Encontro da Associação Brasileira de Ciência Política (ABCP). Gramado-RS, 2012.

FARIA, C. A. P. Ideias conhecimento e políticas públicas: um inventário sucinto das principais vertentes analíticas recentes. RBCS. vol. 18, $\mathrm{n}^{\circ}$. 51, fevereiro/2003.

FERRAREZI, E. R. A reforma do marco legal do terceiro setor no Brasil: a criação da lei das OSCIP (Lei 9.790/99). 2007. Tese. Doutorado em Sociologia. Universidade de Brasília, Brasília, 2007.

FREY, K. Políticas públicas: um debate conceitual e reflexões referentes à prática da análise de políticas públicas no Brasil. Planejamento e políticas pública. n. 21, jun de 2000. 
FREITAS, H. M. R.; CUNHA, M. V. M. Jr.; MOSCAROLA, J. Aplicação de sistemas de software para auxílio na análise de conteúdo. Revista de Administração. São Paulo, 1997.

FUKS, M. Definição da agenda, debate público e problemas sociais: uma perspectiva argumentativa da dinâmica do conflito social. In: XXIV Encontro Anual da ANPOCS. Petrópolis, Rio de Janeiro, 2000.

GINI, S. Repensando a construção da hegemonia empresarial nos 10 anos que mudaram Maringá (1994-2004). Dissertação (Mestrado) Programa de Pós-Graduação em História. Universidade Estadual Maringá. 2007.

Ação empresarial e desenvolvimento econômico local: estratégias políticas e o modelo cidade-empresa. Seminário Nacional de Sociologia \& Política. UFPR, 2009.

GODOY, A. S. Introdução à pesquisa qualitativa e suas possibilidades. RAE. Revista de Administração de Empresas, v. 35, n. 2, p. 57-63. São Paulo, 1995.

GOTTEMS, L.; et. al. O modelo dos múltiplos fluxos de Kingdon na análise de políticas de saúde: aplicabilidades, contribuições e limites. Saúde Soc. São Paulo, v.22, n.2, p. 511-520, 2013.

JANN, W.; WEGRICH, K. Theories of the policy cycle. In FISCHER, F.; MILLER, G.J.; SIDNEY, M.S. Handbook of public policy analysis: theory, politics, and methods. New York, CRC Press Taylor \& Francis Group, 2007.

JOHN, Peter. Analysing public policy: critical political studies. Londres: British Library, 2006.

KINGDON, J. Agendas, alternatives, and public policies. Ann Arbor: University of Michigan, 2003.

Como chega a hora de uma idéia? In: SARAVIA, Enrique e FERRAREZI, Elisabete (org.). Políticas públicas: coletânea. Brasília: ENAP, 2006a. v.1.

Juntando as coisas. In: SARAVIA, Enrique e FERRAREZI, Elisabete (ORG.). Políticas públicas: coletânea. v.1. Brasília: ENAP, 2006 b.

KUHN, T. S. A estrutura das revoluções científicas. São Paulo: Perspectiva, 2013.

LANGLEY, A. Strategies for theorizing from process data. Academy of Management. The Academy of Management Review, v. 24, n. 4, ABI/Inform Global, 1999.

LINDBLOM, C. E. The policy making process. New Jersey: Prentice-Hall Foundations of Modern Political Science Series, 1980.

MINAYO, M. C. S. Ciência, técnica e arte: o desafio da pesquisa social. In: MINAYO, M. C. S. Pesquisa social: teoria, método e criatividade. Petrópolis: Vozes, 2002.

; SANCHEZ, O. Quantitativo e qualitativo: oposição ou complementaridade? Cadernos de Saúde Pública (Fiocruz), Rio de Janeiro, v. IX, n. 3, pp. 239-262, 1993. 
POZZEBON, M. Advanced Topics in Qualitative Research. Doing and publishing qualitative research in international journals. Curso de Inverno. Fundação Getulio Vargas, 2014.

RESENDE, C. A. S. Representação de interesses na Câmara dos Deputados: estratégias, atores e agenda política. Revista Brasileira de Ciência Política, n. 23, pp. 217-258. Brasília, 2017.

SABATIER, P.; JENKINS-SMITH, H. Policy change and learning: an advocacy coalition approach. Colorado: Westview Press, 1993.

SARAVIA, Enrique. Introdução à teoria da política pública. In: SARAVIA, Enrique e FERRAREZI, Elisabete (org.). Políticas públicas: coletânea. Brasília: ENAP, 2006.

; FERRAREZI, E. Políticas públicas. ENAP-Escola Nacional de Administração Pública, v.1, Brasília, 2006.

SERAFIM, M. P; DIAS, R. B. Análise de Política: uma revisão da literatura. Revista do Centro Interdisciplinar de Desenvolvimento e Gestão Social (CIAGS) \& Rede de Pesquisadores em Gestão Social (RGS), v.3, nº 1, 2012.

SILVA, B. F. A recente produção imobiliária no aglomerado metropolitano Paiçandu-SarandiMaringá: novos arranjos, velha lógica. Universidade de São Paulo. Tese (Doutorado) - Faculdade de Arquitetura e Urbanismo da USP. São Paulo, 2015.

SIMÕES, A. Codem apresenta projeto Maringá 2030 à Câmara. Maringá. Disponível em: http://digital.odiario.com/cidades/noticia. Acesso em dez/2016.

SOUZA, Celina. Políticas públicas: uma revisão da literatura. Sociologias, Porto Alegre, ano $8, \mathrm{n}^{\mathrm{o}} 16, \mathrm{jul} / \mathrm{dez}, 2006$, p. 20-45, 2006.

- O Estado da arte em políticas públicas. In: HOLCHMAN, G.; ARRETCHE, M.; MARQUES, E. Políticas públicas no Brasil. Rio de Janeiro: Fiocruz, 2007.

STAKE, R. E. The art of case study researche. Thousand Oaks: Sage Publications, 2005.

TATAGIBA, L. Participação, cultura política e modelos de gestão: a democracia gerencial e suas ambivalências. Tese. Doutorado em Ciências Sociais. Universidade Estadual de Campinas, 2003.

TOCQUEVILLE. Alexis de. A democracia na América. 1ª edição. São Paulo: Folha de São Paulo (Coleção Folha: livros que mudaram o mundo. V. 16), 2010.

TOZONI-REIS. M. F.de C. A pesquisa e a produção de conhecimentos. Educação, Cultura e Desenvolvimento. Unesp. 2005.

VIEIRA, A. Manchete. Comunidade. 02/03/2016. Disponível em: http://www.maringamanchete.com.br/.Acesso em dez/2016.

WINDHOFF-Héritier, A. Policy-Analyse: eine Einführung. Frankfurt am Main/New York: Campus, 1987. 
ZAHARIADIS, Nikolaos. The multiple streams framework: structure, limitations, prospects. In: SABATIER, P. A. Theories of the policy process. Boulder: Westview, 2007. p. 65-92. 